Methods Ambulatory patients with gonarthrosis grade 2 or 3 of Kellgren and Lawrence classification, 30 ? 60 years old, with body mass index $(\mathrm{BMI})<30 \mathrm{~kg} / \mathrm{m}^{2}$ were admitted to the study after comply with inclusion and exclusion criteria. After have been given their informed consent, patients were randomly allocated, in a double-blind way, into treatment groups - Loxoprofen $60 \mathrm{mg}$ t.i.d. or diclofenac $50 \mathrm{mg}$ t.i.d. Duration of treatment was four weeks, and patients were evaluated at pretreatment and every two weeks during therapy for: overall severity of symptoms; pain at rest, on pressure, on movement and nocturnal through a visual analogue scale (VAS); swelling of knee; functional disability; global improvement; side-effects. Laboratory tests were performed in all patients, pre and post treatment.

Results A total of 60 patients was treated ? 30 in each group. There was no significant difference between the groups; $87 \%$ of patients were $>51$ years old. Mean disease duration was $2655 \pm$ 2168 days in LOX and $2086 \pm 1333$ days in DIC (n.s.). 23 patients in LOX and 24 in DIC reported previous treatments with NSAIDs, being diclofenac the most frequent prescribed drug. All parameters evaluated showed statistically significant improvements compared with baseline ( $p<0.0001$ ? chi square) with both treatments; there were no statistically significance differences between treatments groups. GI adverse events occurred in 3 patients $(10 \%)$ of LOX and in $12(40 \%)$ of $\mathrm{DIC}(\mathrm{p}<0.01)$. Epigastralgia was the most prevalent GI event reported (1 in LOX; 7 in DIC). One serious adverse event ? enterorrhagia ? was reported in the diclofenac group, with discontinuation of treatment. Tolerability assessments were classified as both very good and good in 90\% in LOX and in 79\% in DIC ( $\mathrm{p}<0.05$ ). One patient in LOX discontinued therapy due to worsening of the disease, and 5 in DIC ? 4 due to adverse events and 1 worsening of the disease. About $80 \%$ of overall assessment were classified, by investigator and patient, as either very good or good in Loxoprofen group and 70\% in the diclofenac group (n. s.).

Conclusion Loxoprofen $60 \mathrm{mg}$, t.i.d., showed good efficacy accompanied by excellent tolerability and safety in gonarthrosis, which was superior to that of an established NSAID, diclofenac $50 \mathrm{mg}$, t.i.d.

\section{SAT0055 EFFECT OF ROFECOXIB, CELECOXIB, AND NAPROXEN ON BLOOD PRESSURE AND URINARY SODIUM EXCRETION IN ELDERLY VOLUNTEERS}

${ }^{1} \mathrm{Jl}$ Schwartz, ${ }^{2} \mathrm{MP}$ Malice, ${ }^{3} \mathrm{KC}$ Lasseter, ${ }^{4} \mathrm{~GB}$ Holmes, ${ }^{1} \mathrm{KM}$ Gottesdiener, ${ }^{5} \mathrm{~K}$ Brune. ${ }^{1}$ Clinical Pharmacology, Merck \& Co, Inc., Rahway; ${ }^{2}$ Biostatistics, Merck \& Co, Inc., Brussels, Belgium; ${ }^{3}$ Clinical Research, Clinical Pharmacology Associates, Miami; ${ }^{4}$ Clinical Research, SFBC-International, Miami, USA; ${ }^{5}$ Clinical Pharmacology, University Erlangen, Erlangen, Germany

\subsection{6/annrheumdis-2001.430}

Background Nonsteroidal anti-inflammatory drugs (NSAIDs) can affect sodium reabsorption by decreasing the synthesis of renal prostaglandins. Since COX-2 is constitutively expressed in the kidney, it is hypothesised that the effects of COX-2 inhibitors on sodium handling would be similar to non-selective NSAIDs. It is hypothesised moreover that the effects of the two COX-2 inhibitors on sodium handling would be similar.

Objectives This study evaluated the effects of two COX-2 inhibitors [rofecoxib, $25 \mathrm{mg}$ QD and celecoxib, $200 \mathrm{mg}$ BID], a nonselective NSAID [naproxen, $500 \mathrm{mg}$ BID], and placebo on blood pressure (BP) and urinary sodium excretion during a 2-week inhouse administration.
Methods 67 healthy elderly (60 to 80 years) subjects participated in a double-blind, placebo-controlled, parallel-group study. Subjects received a weight-maintaining isocaloric diet $(200 \mathrm{mEq}$ sodium, $0.8 \mathrm{~g} / \mathrm{kg}$ protein, 80 to $120 \mathrm{mEq}$ potassium daily), beginning 8-13 days prior to the first dose of study drug. After attaining sodium balance [based on stable weight (within $0.5 \mathrm{~kg}$ ) and 24-hour urinary sodium between 180 to $220 \mathrm{mEq}$ on 2 consecutive days], subjects were randomised to treatment. Daily 24hour urine collections were obtained. Daily BP measurements were taken at $8 \mathrm{AM}$ and $8 \mathrm{PM}$, and more often (8 AM, Noon, 4 PM, and 8 PM) on Days -1, 1, 7, and 14.

Results Least-Squares mean changes from baseline (SE) for average daily BP on Day 14 (prespecified primary endpoint for BP) are shown in the Table 1 below. There was no significant difference between the active treatment groups in daily average sodium excretion during the first 3 days or over 2 weeks of treatment $(p>0.05)$. No incidence of peripheral oedema occurred during the 2 week treatment. Two subjects experienced elevated systolic BP during the course of the trial (one on each COX-2 inhibitor).

\begin{tabular}{lllll} 
Abstract SAT0055 & Table 1 \\
& Rofecoxib & Celecoxib & Naproxen & Placebo \\
& $\mathrm{N}=17$ & $\mathrm{~N}=17$ & $\mathrm{~N}=17$ & $\mathrm{~N}=16$ \\
\hline Systolic BP(mm Hg) & $3.4(2.0)$ & $4.3(2.0)$ & $3.1(2.0)$ & $-1.4(2.0)$ \\
Diastolic BP(mm Hg) & $0.3(1.0)$ & $0.8(1.0)$ & $-0.4(1.0)$ & $-1.4(1.0)$ \\
\hline
\end{tabular}

Least-Squares Mean Changes from Baseline (SE) for Average Daily BP on Day 14.

Conclusion These results, obtained under well-controlled conditions for two weeks, suggest that the COX-2 selective agents, rofecoxib and celecoxib, have similar effects on BP and urinary sodium excretion; their effect is similar also to that of non-selective NSAIDs.

\section{SAT0056 BISPHOSPHONATE MODULATES ECTOPIC BONE FORMATION AFTER HIP ARTHROPLASTY -WITH JAPANESE CASES-}

Y Yutani, Y Yamano. Department of Orthopaedic Surgery, Osaka City University Medical School, Osaka, Japan

\subsection{6/annrheumdis-2001.431}

Background Ectopic bone formation has been reported as the complication after hip arthroplasty, at the time of paralysis of extremities and cerebral trauma, and in the presence of congenital diseases such as progressive ostosis. Bisphosphonates have been developed as the agent for improving bone metabolism, and are currently used as 1) a derivative in making a radioisotope diagnosis, 2) an inhibitor of bone resorption, 3) a preventive agent for ossification, and 4) an inhibitor of calculus formation in dentistry.

Objectives We have investigated the therapeutic effects of etidronate disodium (EHDP) as a bisphosphonate on ectopic bone formation developing after hip arthroplasty and the indications for administration of EHDP. The patients who had received implant arthroplasty 8 years ago were clinically evaluated, and the influence of EHDP on the prostheses was investigated.

Methods The subjects were the patients who had undergone total hip replacement or hip prosthesis replacement. They consisted of 40 women, and the ages at the time of operation 